\title{
DIFFERENCES IN PAH DESORPTION AND SEDIMENT ORGANIC MATTER COMPOSITION BETWEEN NON-VEGETATED AND RECENTLY VEGETATED FUEL-OILED SEDIMENTS
}

\author{
Elizabeth Guthrie Nichols ${ }^{1}$ and Jennifer Musella ${ }^{2}$ \\ ${ }^{I}$ North Carolina State University, Raleigh, NC, USA \\ ${ }^{2}$ ENSR Consulting and Engineering, Raleigh, NC, USA
}

We assessed the desorption behavior of pyrene, chrysene, phenanthrene, and tri-alkylated $\left(C_{3}\right)$ phenanthrene/anthracenes for non-vegetated and recently vegetated $(<2$ yrs) fueloiled sediments collected from the Indiana Harbor Canal (IHC), Gary, IN. Bulk sediment and humin were analyzed for PAH concentrations, organic matter composition, and PAH desorption behavior. PAH desorption isotherms and kinetics were determined using batch aqueous extractions and a two compartment, first-order kinetic model. Vegetated sediments contained more plant carbon and were more nonpolar and less oxidized than non-vegetated sediments. Desorption kinetics indicated that PAH desorption was primarily controlled by a slow PAH-desorbing fraction $\left(\mathrm{F}_{2}\right)$ of IHC sediments. However, in vegetated sediments, particularly humin, $P A H$ release from a faster $P A H$-desorbing fraction $\left(F_{1}\right)$ increased as did the rates $\left(k_{2}\right)$ of PAH desorption from the dominant slow PAH-desorbing fraction $\left(F_{2}\right)$. We propose that vegetation provides aliphatic, nonpolar carbon to IHC sediments that facilitates more rapid PAH desorption from bulk sediment and humin.

KEY WORDS PAH, sediments, Phragmites, desorption, humin

\section{INTRODUCTION}

Although many polycyclic aromatic hydrocarbons (PAHs) are toxic, their sorption to sediment organic matter (SOM) can reduce their toxicity and availability for biodegradation. The "bioavailable fraction" is often described as those PAHs that desorb into solution or pore water where they are more accessible for uptake by organisms (Alexander, 2000). The bioavailability of PAHs can be evaluated by examining PAH desorption behavior from sediment organic matter (SOM) using biphasic systems of sediment and water to evaluate the amount of PAH(s) desorbed into water over time (Pignatello, 1990; White and Pignatello, 1999). Desorption behavior is generally assumed to control PAH bioavailability (Kukkonen et al., 2003), bioremediation (Cornelissen et al., 1998), and phytoremediation (Ahn et al., 2005). 
The type of SOM and contaminant residence times in SOM can influence the rate and extent of PAH desorption (White et al., 1997; Johnson et al., 2001). Cornelissen et al. (1997b) observed that contaminant desorption occurred in three separate phases: a rapid, slow, and very slow phase. The first phase desorbs in a matter of hours; the slow and very slow phases may take weeks and months, respectively. Rapidly desorbing PAHs are thought to exist on external regions of sediment particles while slowly desorbing PAHs are attributed to retarded diffusion from within the organic matrix or through intraparticle pores (Cornelissen et al., 1997a; Pignatello and Xing, 1996; Huang et al., 2003). In fact, van den Heuvel and van Noort (2003) postulated that slowly desorbing PAHs emanated from "rubbery" pores within condensed SOM while the very slow desorbing PAHs derived from fixed sites within the glassy matrix of SOM. This concept of different PAH mobility in SOM is based on a polymer dual-mode sorption model whereby two domains, glassy and rubbery, simultaneously exist in SOM (Mao and Schmidt-Rohr, 2006). Predominant mechanisms for sorption in the glassy domain include adsorption and absorption while rubbery domains involve primarily linear partitioning or absorption.

Desorption studies may utilize lab-contaminated or weathered, field-contaminated materials. Evaluating contaminant desorption from field soils or sediments better represents how environmental processes alter contaminant uptake, association, and release (Rockne et al., 2002). Prior studies have observed that sediment characteristics such as porosity, organic matter concentration, and specific surface area can influence the fast and slow diffusion of PAHs from field sediments (Shor et al., 2003). In sediments containing plant detrital materials, porosity and $\mathrm{PAH}$, hydrophobicity were observed to influence PAH diffusion from the rapid-release domains of sediment while specific surface area influenced PAH diffusion from slow-release domains of sediment (Shor et al., 2003).

Specific SOM structures may also influence PAH desorption behavior. Aromatic carbon (Gunasekara and Xing, 2003; Yang et al., 2004), aliphatic carbon (Chefetz et al., 2000; Salloum et al., 2002; Mao et al., 2002), black carbon (Oen et al., 2006; Cornelissen et al., 2005), diagenetically-aged carbon (Johnson et al., 2001; Rockne et al., 2002), and polarity (Rutherford et al., 1992; Kile et al., 1999; Xing et al., 1994) may impart disparate desorption behavior ranging from rapidly desorbing, slow desorbing, very slow desorbing, to desorption resistant fractions of contaminant (Cornelissen et al., 1997b; Shor et al., 2003; Saffron et al., 2006). Diagenetically-aged SOM, such as coke, coals, and kerogen, exhibit slow or resistant PAH desorption behavior due to weathering processes that remove polar functional groups while increasing the condensed, aromatic carbon domains of SOM (Johnson et al., 2001; Gunasekara and Xing, 2003). Less mature geosorbents may slow or enhance PAH desorption due to either rigid, crystalline (glassy) or more amorphous, mobile (rubbery) aliphatic carbon domains, respectively (Gunasekara and Xing, 2003; Oren and Chefetz, 2005; Chen and Xing, 2005; Salloum et al., 2002). The presence or absence of polar functional groups within SOM domains appears to correlate with faster and slower PAH desorption behavior, respectively (Chen et al., 2005).

This study assessed PAH desorption behavior from heavily contaminated fuel-oiled near shore sediments collected from the Indiana Harbor Canal (IHC), Gary, IN. IHC sediments were either not vegetated or recently colonized by Phragmites australis, the common reed plant $(<2 \mathrm{yrs})$. We evaluated the organic matter composition of IHC sediment fractions and determined PAH desorption isotherms for pyrene, phenanthrene, chrysene, and $\mathrm{C}_{3}$-phenanthrene/anthracenes. The amount and extent of PAH desorption and PAH desorption kinetics were assessed in light of differences between vegetated and non-vegetated sediment organic matter composition. We hypothesized that vegetation 
would alter sediment organic matter composition and PAH desorption behavior relative to non-vegetated sediment fractions.

\section{MATERIALS AND METHODS}

\section{Sediment Sampling, Fractionation, and Characterization}

The Indiana Harbor Canal (IHC) is a heavily industrialized area with historic petroleum contamination of soils and sediments. Diesel fuel is the dominant contaminant source at the site and a petroleum sheen persists in canal waters (Sand Creek Consultants, Inc., 2002). Total petroleum hydrocarbon (TPH) concentrations range from $2 \%$ to $43 \%$ of sediment mass. Disturbance of the site in 2002 resulted in colonization by Phragmites australis, the common reed plant.

Sediment samples were collected by removing approximately $10 \mathrm{~cm}$ of sediment by hand trowel or shovel within a 2-m-diameter circle of vegetated or non-vegetated sediments. Sediment samples were collected at 6 to 9 locations for each plant species and 3 locations of non-vegetated sediments. Non-vegetated sediments were composited at the site prior to storage and transport. In vegetated areas, plant litter and debris were removed from the sediment surface after which sediments with plants roots were removed in toto. Visible plant roots and plant material were removed from sediments prior to mixing sediments together for each plant species. Sediments were transported in plastic bags at $0^{\circ} \mathrm{C}$. Prior to chemical fractionation and analyses, small visual root residuals were removed, and sediments were sieved $(2 \mathrm{~mm})$ and homogenized again in ceramic bowls.

The original composite sediments samples are referred to as bulk sediment fractions. Aliquots of bulk sediments (10-15 g) were freeze-dried then chemically fractionated to obtain de-ashed humin fractions according to previously described methods in Gregory et al., (2005, 2008). Briefly, sediments were lipid-extracted twice then extracted with sodium hydroxide under a nitrogen headspace to remove humic and fulvic acids. Humin was de-ashed using hydrochloric acid ( $\mathrm{HCl})$ and hydrofluoric acid (HF). To evaluate our fractionation and extraction procedures, diluted Alaskan north slope crude oil (ANS) was spiked with deuterated chrysene (CHY-d $\left.\mathrm{d}_{12}, 3.5 \mu \mathrm{g} / \mathrm{mL}\right)$ and added to a soil with no known petrogenic contamination. Recovery was $100 \%$ (Gregory et al., 2005). Humin represents the sediment organic matrix after extraction with dichloromethane (DCM) and alkaline salts to remove lipids and humic/fulvic acids, respectively. De-ashed humin represents humin after extraction with $\mathrm{HF} / \mathrm{HCl}$ to remove the mineral matrix.

Bulk sediment and de-ashed humin fractions were analyzed for black carbon (BC) content by acidification of freeze-dried samples with $1.2 \mathrm{M}$ hydrogen chloride vapor then thermal oxidation at $375^{\circ} \mathrm{C}$ for 24 hours followed by total organic carbon measurement (Gelinas et al., 2001; Wakeham et al., 2004). Elemental analyses of carbon, hydrogen, nitrogen, and oxygen were determined by high-temperature combustion and/or pyrolysis techniques on a ConFlo III Elemental Analyzer (Thermo Electron North America LLC, West Palm Beach, FL). One sediment fraction and a set of duplicate sediment fractions, making up $25 \%$ of samples analyzed, were sent to Huffman Labs (Golden, CO) for quality assurance and quality control. Standard methods ASTM D-4129 (C and H), ASTM D-5373 $(\mathrm{N})$, and ASTM D-5622 (O) were used. Percent relative standard deviation (RSD) was within $10 \%$ for samples analyzed.

Desorption experiments. Desorption experiments used an aqueous batch technique that was adapted from Cornelissen et al. (1997a). Three replicate PAH desorption 
measurements were taken at seven time points over a 120-day period. A mixture of sediment $(\approx 5 \mathrm{~g}$ dry weight $)$, mercuric chloride $\left(\mathrm{HgCl}_{2} ;\right.$ biocide, $\left.2 \mathrm{~g} / \mathrm{L}\right)$, and distilled, deionized water was added to $50 \mathrm{~mL}$ Teflon Oak Ridge centrifuge tubes. Samples were capped, sealed with Teflon $^{\mathrm{TM}}$ tape, and allowed to shake for time periods ranging from 24 hours to 120 days at $20 \pm 2^{\circ} \mathrm{C}$.

At each designated time point, samples were removed from the shaker table and centrifuged for 20 minutes at $2500 \mathrm{rpm}$. The aqueous portion $(\sim 35 \mathrm{~mL})$ was decanted into a new $50 \mathrm{~mL}$ Teflon ${ }^{\mathrm{TM}}$ Oak Ridge tube and allowed to sit for 24 hours. The aqueous phase of each sample was replaced with a fresh aliquot of $40 \mathrm{~mL}$ of $\mathrm{HgCl}_{2}$ solution and shaken until the next time point. An aliquot of the decanted aqueous phase was removed with a 10 $\mathrm{mL}$ pipette, transferred to another $50 \mathrm{~mL}$ Teflon ${ }^{\mathrm{TM}}$ Oak Ridge centrifuge tube, and extracted with $5 \mathrm{~mL}$ of dichloromethane (DCM); the DCM layer was removed and transferred to a $40 \mathrm{~mL}$ amber EPA vial with anhydrous sodium sulfate $\left(\mathrm{Na}_{2} \mathrm{SO}_{4}\right)$ to remove any residual water. DCM extracts were evaporated under a gentle stream of $\mathrm{N}_{2}$ gas to approximately 1 $\mathrm{mL}$ and transferred to a gas chromatography/mass spectrometry (GC/MS) vial using a 500 $\mu \mathrm{L}$ syringe. Sample volumes were adjusted to $1 \mathrm{~mL}$, sealed, and stored at $0^{\circ} \mathrm{C}$ until GC/MS analysis. DCM extracts of bulk sediment and de-ashed humin were first loaded onto neutral activated alumina columns prior to analysis by GC/MS. DCM extracts of sediments were concentrated to $5 \mathrm{~mL}$.

GC/MS SIM. Both DCM extracts of sediments and aqueous desorption samples were spiked with deuterated phenanthrene $\left(d_{10}, 500 \mathrm{ng} / \mathrm{mL}\right)$ and benzo[ $\left.a\right]$ pyrene $\left(d_{8}, 505\right.$ $\mathrm{ng} / \mathrm{mL}$ ) as internal standards prior to GC/MS analysis. Extracts were analyzed for $42 \mathrm{PAHs}$ using a modified method of EPA 8270 (USEPA, 1986) as described in Luellen and Shea (2002). GC/MS select ion monitoring (SIM) mode analyses were conducted on a HP5890 Series II GC equipped with electronic pressure control connected to an HP5970 or HP5972 MSD using a Restek $30 \mathrm{~m} \times 0.25 \mathrm{~mm}$ Rtx-5 (film thickness $0.25 \mu \mathrm{m}$ ) MS w/Integra-Guard column.

Data analysis. Desorption from sediment can be described by the following two compartment, first-order kinetic model shown in Equation 1 (Oen et al., 2006; Cornelissen et al., 1997b and 1998):

$$
\frac{\mathrm{S}_{\mathrm{t}}}{\mathrm{S}_{0}}=\mathrm{F}_{1} \mathrm{e}^{-\mathrm{k}_{1} * \mathrm{t}}+\mathrm{F}_{2} \mathrm{e}^{-\mathrm{k}_{2} * \mathrm{t}}
$$

$\mathrm{S}_{\mathrm{t}}$ and $\mathrm{S}_{0}$ are the observed sediment-sorbed amounts at time $t$ (days) and at the start of the experiment. $F_{1}$ and $F_{2}$ represent two kinetically different desorbing fractions of the contaminant present in the sediment. $\mathrm{F}_{1}$ represents a faster PAH-desorbing fraction in sediment, and $\mathrm{F}_{2}$ represents a second, slower PAH desorbing fraction. The first-order rate constants for $\mathrm{F}_{1}$ and $\mathrm{F}_{2}$ are noted as $k_{1}$ and $k_{2}\left(\right.$ days $^{-1}$ ). Because PAHs should desorb from the $\mathrm{F}_{1}$ fraction at a faster rate $\left(k_{1}\right)$ than their rate of desorption $\left(k_{2}\right)$ from the slower $\mathrm{F}_{2}$ fraction, one assumption of the model is that $k_{1} \gg k_{2}$. The model was fitted to observed PAH desorption data to estimate rate constants $\left(k_{1}, k_{2}\right)$ and desorbing compartments $\left(\mathrm{F}_{1}\right.$ and $\mathrm{F}_{2}$ ) by minimizing the cumulative squared residuals between observed and calculated values of $\ln \left(\mathrm{S}_{\mathrm{t}} / \mathrm{S}_{0}\right)$ in Equation 1 under the boundary condition that $\mathrm{F}_{1}+\mathrm{F}_{2}=1$. The best-fit adjustable parameter values were found using the solver function in Microsoft Excel ${ }^{\circledR} 7.0$ (Denton, 2000).

Concentrations of select PAHs between vegetated (Phragmites australis) and nonvegetated sediment fractions (Table 1) were compared to determine if vegetation 
Table 1 Individual PAH concentrations ( $\mu \mathrm{g} / \mathrm{g}$ sediment) for fuel-oiled sediments at Indiana Harbor Canal, Gary, IN

\begin{tabular}{|c|c|c|c|c|}
\hline & \multicolumn{4}{|c|}{ Indiana Harbor Canal (IHC) } \\
\hline & \multicolumn{2}{|c|}{ Bulk sediment } & \multicolumn{2}{|c|}{ De-ashed humin } \\
\hline & Non-vegetated & Phragmites & Non-vegetated & Phragmites \\
\hline Phenanthrene $^{\mathrm{a}}$ & $8.2 \pm 0.51$ & $7.2 \pm 0.58$ & $0.10 \pm 0.002^{\mathrm{B}}$ & $0.15 \pm 0.011^{\mathrm{B}}$ \\
\hline Pyrene $^{a}$ & $457 \pm 36.7^{\mathrm{A}}$ & $361 \pm 23.6^{\mathrm{A}}$ & $0.42 \pm 0.014^{\mathrm{B}}$ & $0.2 \pm 0.002^{\mathrm{B}}$ \\
\hline Chrysene $^{\mathrm{a}}$ & $229 \pm 33.9$ & $205 \pm 15.7$ & $0.09 \pm 0.01^{\mathrm{B}}$ & $0.47 \pm 0.087^{\mathrm{B}}$ \\
\hline $\mathrm{C}_{3}$-Phen/anth ${ }^{\mathrm{a}, \mathrm{b}}$ & $346 \pm 27.2^{\mathrm{A}}$ & $229 \pm 19.07^{\mathrm{A}}$ & $0.12 \pm 0.01$ & $0.12 \pm 0.01$ \\
\hline
\end{tabular}

significantly altered PAH concentrations in sediments. Statistical significance was determined using a one-tailed student's t-test $(p<0.05)$ where the mean of a vegetated sediment fraction was compared to a non-vegetated sediment fraction. Correlations between individual PAH concentrations and the distribution ratios between $\left(\mathrm{F}_{2} / \mathrm{F}_{1}\right)$ were determined by linear regression.

\section{RESULTS AND DISCUSSION}

\section{PAH Concentrations and Sediment Organic Matter Composition}

We evaluated phenanthrene, pyrene, and chrysene desorption behavior and kinetics so that results could be compared to other published PAH desorption data for fieldcontaminated sediments. We included $\mathrm{C}_{3}$-phenanthrenes/anthracenes in this study because petrogenic PAH sources, such as petroleum, contain alkylated PAHs that are not often studied for their toxicity, fate, and transport. Alkylated PAHs are useful indicators of PAH attenuation and weathering (Gregory et al., 2005) and are certainly present at phytoremediation sites contaminated with petroleum wastes.

Of the four PAHs evaluated in this desorption study (Table 1), only pyrene had lower mean concentrations in both vegetated bulk and humin fractions relative to non-vegetated sediment fractions (Student $t$ test, $\mathrm{p}<0.05$ ). Phenanthrene and chrysene concentrations were similar for bulk sediment fractions but significantly higher for vegetated humin. Mean $\mathrm{C}_{3}$-phenanthrenes/anthracenes concentrations were significantly lower in vegetated bulk sediments but similar for both vegetated and non-vegetated humin (Table 1; Student $t$ test, $\mathrm{p}<0.05)$.

The same sediments used for this desorption study were also characterized by Gregory et al. (2008). We previously reported total PAH concentrations of 42 alkylated and nonalkylated PAHs for the same IHC sediment fractions (Gregory and Nichols, 2008). Overall, Phragmites bulk sediment fractions had lower mean concentrations of TPAH than nonvegetated bulk sediments; whereas, total PAH concentrations in humin fractions were similar. 
Table 2 Percent organic carbon (OC), percent modern carbon (MC) ${ }^{\mathrm{b}}$, percent black carbon (BC), elemental analyses, atomic ratios, and polarity index for fuel-oiled sediments at Indiana Harbor Canal, Gary, IN

\begin{tabular}{|c|c|c|c|c|}
\hline & \multicolumn{4}{|c|}{ Indiana Harbor Canal (IHC) } \\
\hline & \multicolumn{2}{|c|}{ Bulk sediment } & \multicolumn{2}{|c|}{ De-ashed humin } \\
\hline & Non-vegetated & Phragmites & Non-vegetated & Phragmites \\
\hline$\%$ Organic $\mathrm{C}^{\mathrm{a}, \mathrm{c}}$ & $14 \pm 0.96$ & $13 \pm 0.14$ & $4.6 \pm 0.31^{\mathrm{B}}$ & $3.7 \pm 0.12^{\mathrm{B}}$ \\
\hline$\%$ Modern $\mathrm{C}^{\mathrm{a}, \mathrm{c}}$ & $8.2 \pm 0.075^{\mathrm{A}}$ & $21 \pm 0.11^{\mathrm{A}}$ & $4.4 \pm 0.073^{\mathrm{B}}$ & $8.2 \pm 0.075^{\mathrm{B}}$ \\
\hline$\% \mathrm{C}^{\mathrm{a}}$ & $17 \pm 0.17$ & $16 \pm 0.51$ & $0.97 \pm 0.028^{\mathrm{B}}$ & $0.31 \pm 0.0035^{\mathrm{B}}$ \\
\hline$\% \mathrm{H}^{\mathrm{a}}$ & $2.5 \pm 0.0079^{\mathrm{A}}$ & $2.0 \pm 0.086^{\mathrm{A}}$ & $0.10 \pm 0.01^{\mathrm{B}}$ & $0.06 \pm 0.01^{\mathrm{B}}$ \\
\hline$\% \mathrm{~N}^{\mathrm{a}}$ & $0.18 \pm 0.003^{\mathrm{A}}$ & $0.21 \pm 0.001^{\mathrm{A}}$ & $0.02 \pm 0.001^{\mathrm{B}}$ & $0.01 \pm 0.001^{\mathrm{B}}$ \\
\hline$\% \mathrm{O}$ & $5.1 \pm 0.29^{\mathrm{a}, \mathrm{A}}$ & $2.8 \pm 0.026^{\mathrm{a}, \mathrm{A}}$ & $1.2 \pm 0.24^{\mathrm{b}}$ & $0.29 \pm 0.021^{\mathrm{b}}$ \\
\hline $\mathrm{H} / \mathrm{C}^{\mathrm{a}}$ & $0.14 \pm 0.002^{\mathrm{A}}$ & $0.13 \pm 0.001^{\mathrm{A}}$ & $0.08 \pm 0.023^{\mathrm{B}}$ & $0.17 \pm 0.009^{\mathrm{B}}$ \\
\hline $\mathrm{O} / \mathrm{C}$ & $0.29 \pm 0.009^{\mathrm{a}, \mathrm{A}}$ & $0.17 \pm 0.004^{\mathrm{a}, \mathrm{A}}$ & $1.2 \pm 0.22^{\mathrm{b}}$ & $0.93 \pm 0.063^{\mathrm{b}}$ \\
\hline $\begin{array}{l}\text { Polarity index }{ }^{b} \mathrm{PI}= \\
\qquad(\mathrm{O}+\mathrm{N}) / \mathrm{C}\end{array}$ & $0.30 \pm 0.01$ & $0.19 \pm 0.004$ & $1.5 \pm 0.19$ & $0.92 \pm 0.06$ \\
\hline$\% \mathrm{BC}^{\mathrm{a}, \mathrm{d}}$ & $17 \pm 3.0$ & $21 \pm 2.9$ & $7.1 \pm 1.3^{\mathrm{B}}$ & $4.5 \pm 0.31^{\mathrm{B}}$ \\
\hline
\end{tabular}

${ }^{\text {a}}$ Values are means of triplicates \pm one standard deviation;

${ }^{b}$ Values are means of duplicates \pm one standard deviation;

${ }^{\mathrm{c}}$ Gregory et al., 2008; and

d\% black carbon of total organic carbon; organic carbon after heating (375 C, $24 \mathrm{~h})$.

${ }^{A}$ Denotes mean values that are significantly different [Student $t$-test $\left.(p<0.05)\right]$ between non-vegetated and Phragmites bulk sediments.

${ }^{\mathrm{B}}$ Denotes mean values that are significantly different [Student $t$-test $\left.(p<0.05)\right]$ between non-vegetated and Phragmites de-ashed humin.

We also previously reported differences in the organic matter composition (modern carbon and percent organic carbon) between vegetated and non-vegetated IHC sediments in Gregory et al. 2008 and have provided those data in Table 2 as they are relevant to interpretation of PAH desorption behavior. Phragmites IHC sediment contained more modern carbon, or plant-derived carbon, than non-vegetated IHC sediment fractions. Natural abundance radiocarbon carbon measurements determine the amount of ${ }^{14} \mathrm{C}$ present in a sample to "age date" or "carbon-date" a particular material. Modern plants fix ${ }^{14} \mathrm{CO}_{2}$ from the atmosphere and, therefore, have a modern ${ }^{14} \mathrm{C}$ signature as do their consumers. Petroleum, derived from ancient plants, is old and no longer contains ${ }^{14} \mathrm{C}$-photosynthate due to radioactive decay; thus, petroleum products have $0 \%$ modern carbon content in contrast to modern plants (100\%). This relationship can be exploited at sites with significant petrogenic contamination and vegetation to evaluate how much plant carbon (modern carbon) is present in contaminated media (Gregory et al., 2005).

We were surprised to observe significant increases of plant carbon in vegetated IHC sediment and humin after only two years of Phragmites growth. In contrast, total organic carbon (\% OC) did not change or was actually lower in Phragmites sediments than non-vegetated sediments (Gregory et al., 2008; see Table 2). Increased plant carbon content with negative or similar organic carbon content suggests increased biogenic carbon turnover, or humification, in vegetated sediment fractions. As plant organic matter undergoes humification and diagenesis, $\mathrm{H} / \mathrm{C}$ and $\mathrm{O} / \mathrm{C}$ atomic ratios decline as $\mathrm{SOM}$ is biologically processed, physically condensed, and chemically reduced (Johnson et al., 2001; Yang et al., 2004). O/C and H/C ratios were lower for vegetated bulk sediments 
(Table 2), which indicates that vegetated bulk sediments were less oxidized, more reduced, and more "humified" than non-vegetated bulk sediments. Vegetated humin was also less oxidized $(\mathrm{O} / \mathrm{C})$ than non-vegetated humin but also less reduced $(\mathrm{H} / \mathrm{C})$. These mixed results are not unexpected given that aliphatic carbon, such as plant and microbial lipids, are preserved in humin via humification processes (Salloum et al., 2002).

Elemental analyses can be used to describe the degree of SOM condensation and to evaluate the polarity of vegetated and non-vegetated sediment fractions (Huang and Weber, 1997; Mao et al., 2002; Kang and Xing, 2005). Elemental data in Table 2 was used to calculate a polarity index (PI) that is the weight ratio of $\mathrm{O}+\mathrm{N}$ to C (Rutherford et al., 1992; Xing et al., 1994). Polarity indices were lower for vegetated fractions than non-vegetated fractions and indicate that Phragmites sediment and humin were more nonpolar than non-vegetated sediment and humin.

Black carbon generally has low atomic ratios and low polarity and is an important component of SOM that influences PAH desorption and bioavailability (Corneillesen $e t$ al., 2005). Black carbon may comprise 1 to $20 \%$ (median of $9 \%$ ) of the total organic carbon present in sediment (Corneillesen et al., 2005). BC content was similar between vegetated and non-vegetated bulk sediment fractions, but BC content was greater for non-vegetated humin than Phragmites humin (Table 2). BC content of bulk sediments (17-21\%) was two to three times greater than $\mathrm{BC}$ content of humin fractions (4-7\%) which may explain why bulk sediment fractions were more nonpolar and reduced than humin fractions. However, greater $\mathrm{BC}$ content of non-vegetated sediment fractions does not explain increased atomic ratios and polarity indices for non-vegetated sediments relative to vegetated sediment fractions.

Phragmites australis is known to translocate oxygen and a significant portion of its photosynthate carbon to sediments via its roots (Minchinton, 2002), and we observed more plant carbon in vegetated IHC sediment (Gregory et al., 2008). Fifty percent of Phragmites litter becomes substrate material for soils and sediments (Asaeda et al., 2002), and this material would be more polar and oxidized than weathered fuel-oil. We also observed that Phragmites bulk sediments contained more weathered PAHs than non-vegetated bulk sediments (Gregory et al., 2008) which should contribute more oxidized and polar PAH metabolites to the SOM matrix. Thus, we anticipated that vegetated SOM composition would be more polar and oxidized than non-vegetated SOM and were surprised that elemental data and atomic ratios indicated otherwise. Vegetated SOM was actually less oxidized and more nonpolar than non-vegetated SOM.

Recently, Cofield et al. (2007) evaluated the effect of vegetation on manufactured, gas plant soil hydrophobicity and observed that vegetated, manufactured gas plant soils were more hydrophobic (nonpolar) than unplanted soils after one year of phytoremediation. Their research indicated that plant residues and microbially-derived lipids were the primary factors controlling soil hydrophobicity not contamination (Cofield et al., 2007, references therein). Their findings suggest that more reduced and nonpolar Phragmites IHC sediment reflect Phragmites carbon influx, plant carbon turnover, and associated rhizosphere microbial activity.

What, then, are the potential impacts of more nonpolar OM matrices on PAH attenuation and desorption? Generally, more reduced, nonpolar OM strongly sorbs PAHs, slows PAH desorption, and reduces PAH bioavailability (Huang and Weber, 1997; Johnson et al., 2001; Wang et al., 2005). However, we and Cofield et al. (2007) observed significant attenuation of PAHs in more nonpolar, vegetated contaminated SOM relative to more polar, non-vegetated SOM controls. Greater PAH weathering and reductions in PAH 
Table 3 Mass amounts and percent PAH desorbed from bulk sediment and humin fractions of non-vegetated and vegetated IHC sediments

\begin{tabular}{|c|c|c|c|c|}
\hline & \multicolumn{2}{|c|}{ Non-vegetated } & \multicolumn{2}{|c|}{ Phragmites } \\
\hline & $\begin{array}{l}\text { Total desorbed } \\
\text { (ng/g) }\end{array}$ & $\%$ Total PAH & $\begin{array}{l}\text { Total desorbed } \\
\text { (ng/g) }\end{array}$ & $\%$ Total PAH \\
\hline \multicolumn{5}{|c|}{ Bulk sediments } \\
\hline Phen $^{\mathrm{a}}$ & $17 \pm 0.15$ & $0.20 \pm 0.0019$ & $17 \pm 0.29$ & $0.24 \pm 0.0040$ \\
\hline Pyrene $^{\mathrm{a}}$ & $74 \pm 11^{\mathrm{A}}$ & $0.02 \pm 0.002$ & $40 \pm 3.4^{\mathrm{A}}$ & $0.01 \pm 0.001$ \\
\hline Chy ${ }^{\mathrm{a}}$ & $28 \pm 3.2^{\mathrm{A}}$ & $0.01 \pm 0.001$ & $6.5 \pm 0.45^{\mathrm{A}}$ & $0.003 \pm 0.0002$ \\
\hline $\mathrm{C}_{3}-\mathrm{Phen}^{\mathrm{a}, \mathrm{b}}$ & $42 \pm 4.1^{\mathrm{A}}$ & $0.01 \pm 0.001^{\mathrm{A}}$ & $20 \pm 2.0^{\mathrm{A}}$ & $0.01 \pm 0.001^{\mathrm{A}}$ \\
\hline \multicolumn{5}{|c|}{ De-ashed humin } \\
\hline Phen $^{\mathrm{a}}$ & $23 \pm 1.8$ & $22 \pm 1.7$ & $26 \pm 0.46$ & $17 \pm 0.31$ \\
\hline Pyrene $^{a}$ & $7.0 \pm 0.41$ & $1.7 \pm 0.10$ & $7.9 \pm 0.29$ & $3.9 \pm 0.14$ \\
\hline Chy ${ }^{\mathrm{a}}$ & $3.2 \pm 0.35$ & $3.6 \pm 0.39$ & $2.6 \pm 0.44$ & $0.6 \pm 0.09$ \\
\hline $\mathrm{C}_{3}-\mathrm{Phen}^{\mathrm{a}, \mathrm{b}}$ & $7.6 \pm 0.79$ & $6.4 \pm 0.66$ & $7.2 \pm 0.76$ & $5.9 \pm 0.63$ \\
\hline
\end{tabular}

$\%$ Total PAH refers to the amount of each individual PAH desorbed divided by the its total extractable concentration in that sediment fraction.

${ }^{a}$ Values are means $(n=3) \pm$ one standard deviation.

${ }^{\mathrm{b}} \mathrm{C}_{3}$-phenanthrene/anthracenes.

${ }^{\text {A }}$ Denotes mean values that are significantly different [Student $t$-test $(p<0.05)$ ] between non-vegetated and Phragmites bulk sediments.

concentrations for vegetated sediments suggest enhanced PAH release from vegetated sediments relative to non-vegetated sediments.

PAH desorption. To normalize PAH desorption data to PAH concentrations in sediments, we determined the percent PAH desorbed which is defined as the total cumulative PAH desorbed in 120 days divided by the total sediment PAH concentration. Consistent trends among all PAHS were not observed. $\mathrm{C}_{3}$-phenanthrene desorbed similar percentages for vegetated and non-vegetated sediment fractions (Table 3; Student $t$ test, $\mathrm{p}<0.05$ ). Percent chrysene desorbed was greater for non-vegetated bulk sediment and humin fractions. Percent pyrene desorption was greater for non-vegetated bulk sediments and vegetated humin, and percent phenanthrene desorption was greater for Phragmites bulk sediment and non-vegetated humin.

Total PAH desorbed was less than $0.24 \%$ for bulk sediments and between 0.6 and $22 \%$ for humin fractions. Other studies have observed PAH desorption from 1 to $90 \%$ for field-contaminated sediments (Oen et al., 2006). Differences in desorption behavior among different sediments can also be attributed to organic matter composition, sources of PAH contamination, and the extent of weathering (Shor et al., 2003; Oen et al., 2006).

A greater percent of PAH desorbed from humin fractions than bulk sediment fractions. Results also show that more phenanthrene desorbed (\% desorbed) from bulk sediment and humin than the other PAHs (Table 3). Other studies have observed that more hydrophillic PAHs desorb less than more hydrophobic PAHs due to the release or degradation of lower molecular weight PAHs in highly weathered sediments (Oen et al., 2006; Shor et al., 2003). Phenanthrene desorption did not follow this trend which would suggest that IHC fuel-oiled sediments retain a significant, non-weathered fuel-oil fraction.

Desorption rate constants and desorbing fractions. To better evaluate differences in rates of PAH desorption between vegetated and non-vegetated sediment 
fractions, rate constants for PAH desorption from fast and slow PAH desorbing-sediment compartments were calculated using Equation 1. The observed fractional desorption data for bulk sediments (Figure 1) and humin (Figure 2) of each PAH show a change in slope that indicates a more rapid then slower phase of PAH release over time. Biphasic desorption isotherms are commonly observed for PAH desorption from field-contaminated sediments.

The solid data points in Figures 1 and 2 represent means of observed desorption measurements $(\mathrm{n}=3 ; \pm$ one standard deviation) at specific time points over 120 days. Lines were obtained by exponential curve fitting and represent calculated values using the empirical, first-order, two-compartment model described in equation 1. Fitting the observed data to Equation 1 provides rate constants $\left(k_{1}, k_{2}\right)$ and the faster $\left(\mathrm{F}_{1}\right)$ and slower $\left(\mathrm{F}_{2}\right) \mathrm{PAH}$ desorbing- fractions in the sediment.

Time, weathering, and sorption to organic matter reduce PAH bioavailability; hence, PAH desorption is primarily controlled by the slower desorbing PAH fraction $\left(\mathrm{F}_{2}\right)$ in weathered, field-contaminated sediments. The $\mathrm{F}_{2}$ fraction is typically quite large $(0.997)$ relative to the faster desorbing fraction, $\mathrm{F}_{1}(0.0032)$, in field sediments, and PAH release from the $\mathrm{F}_{2}$ fraction is much slower $\left(10^{-4} / \mathrm{day} ; k_{2}\right)$ than from the $\mathrm{F}_{1}$ fraction $\left(10^{-0} /\right.$ day; $k_{1}$ ). Larger $\mathrm{F}_{1}$ fractions suggest more $\mathrm{PAH}$ release from sediment. Faster PAH release from either $\mathrm{F}_{1}$ or $\mathrm{F}_{2}$ fractions would be evident by increases in their respective rate constants, $\left(k_{1}\right.$, $k_{2}$ ). If vegetation increases PAH desorption from IHC sediments, then values of $\mathrm{F}_{1}$, its rate constant $\left(k_{1}\right)$, and the rate constant of $\mathrm{F}_{2}\left(k_{2}\right)$ should also increase. For purposes of clarity, we show only the relative size of the faster desorbing PAH fractions $\left(\mathrm{F}_{1}\right)$ in vegetated and non-vegetated sediments in Table 4 . The slower desorbing sediment compartment $\left(\mathrm{F}_{2}\right)$ can be readily determined by $\mathrm{F}_{2}=1-\mathrm{F}_{1}$.

Larger $F_{1}$ values were generally observed more for vegetated fractions than their respective non-vegetated fractions (Table 4). $F_{1}$ values in vegetated bulk sediment were greater for all PAHs except phenanthrene, and $F_{1}$ values in vegetated humin were greater for all PAHs except $\mathrm{C}_{3}$-phenanthrenes. Both vegetated and non-vegetated humin appear to contain a larger $F_{1}$ fraction than their respective bulk sediments. $F 1$ values for humin were greater than bulk sediment F1 values for all PAHs; hence, a greater percent of each PAH was released from humin than bulk sediment as summarized in Table 3.

The rate of PAH release $\left(k_{1}\right)$ from $\mathrm{F}_{1}$ fractions did not differ between vegetated and non-vegetated bulk sediments, and $\mathrm{F}_{1}$ desorption rate constants $\left(k_{1}\right)$ were on the order of $10^{-1} /$ day (Table 4$)$. Thus, vegetated bulk sediments had greater $F_{1}$ fractions but the same PAH release rates as non-vegetated bulk sediments. The rate of PAH release $\left(k_{2}\right)$ from $\mathrm{F}_{2}$, the fraction that primarily controls $\mathrm{PAH}$ desorption, was greater in vegetated bulk sediments.

For humin fractions, phenanthrene and chrysene $k_{1}$ values were greater in nonvegetated humin while pyrene and $\mathrm{C}_{3}$-phenanthrenes $k_{1}$ values were greater in vegetated humin (Table 4). As observed in bulk sediments, the rate of PAH release $\left(k_{2}\right)$ from $\mathrm{F}_{2}$ was greater in vegetated humin. $\mathrm{F}_{1}$ desorption rate constants $\left(k_{1}\right)$ were on the order of $10^{\circ}$ to $10^{-2} /$ day for humin fractions and were more variable than bulk sediment values. $\mathrm{F}_{2}$ desorption rate constants $\left(k_{2}\right)$ were on the order of $10^{-4}$ to $10^{-5}$ day and often 5 to 10 times greater than bulk sediment values.

As expected, $\mathrm{F}_{2}$ desorption rate constants $\left(k_{2}\right)$ of $10^{-4}$ to $10^{-5}$ /day were much lower $\mathrm{F}_{1}$ desorption rate constants $\left(k_{1}\right)$. IHC $\left(k_{2}\right)$ rate constants were lower than other published values $\left(10^{-3} /\right.$ day) (Kan et al., 2000). Translating our data to compare to other published rate constants $\left(\mathrm{h}^{-1}\right)$ yielded rate constants for bulk sediments that ranged from $10^{-2} / \mathrm{h}$ for 

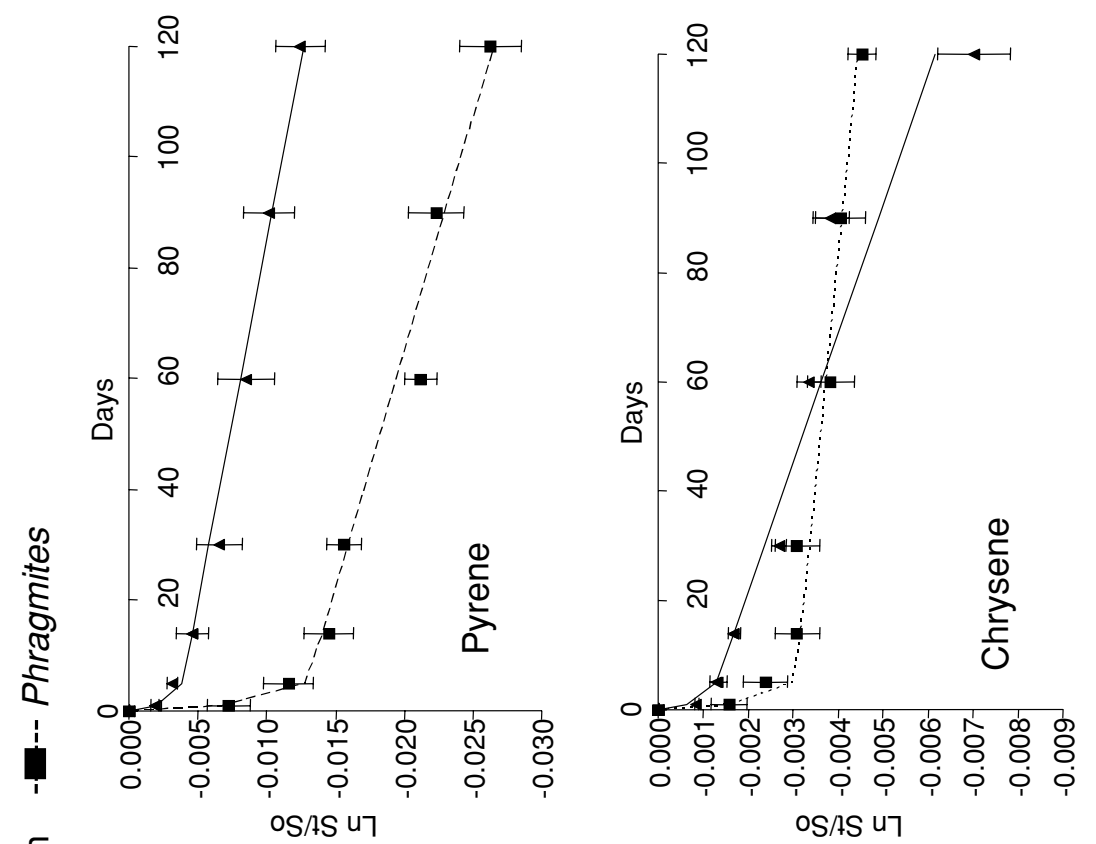

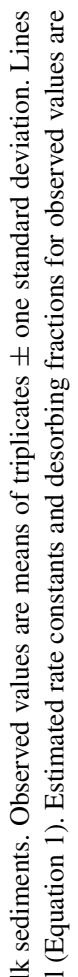
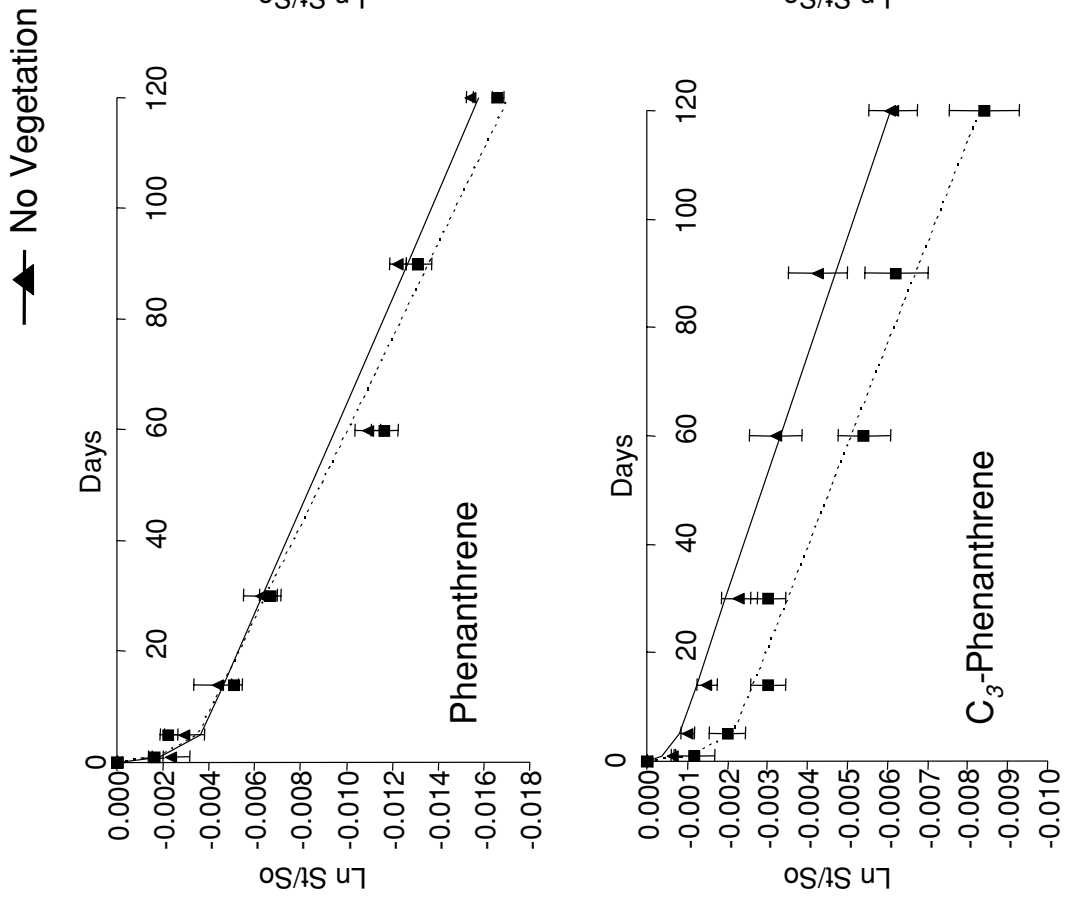

言 ㅁ⿺⿻一𠃋

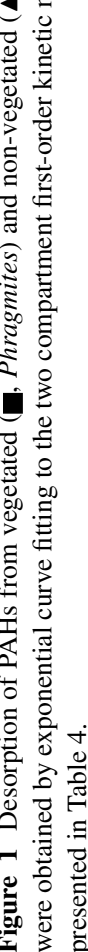



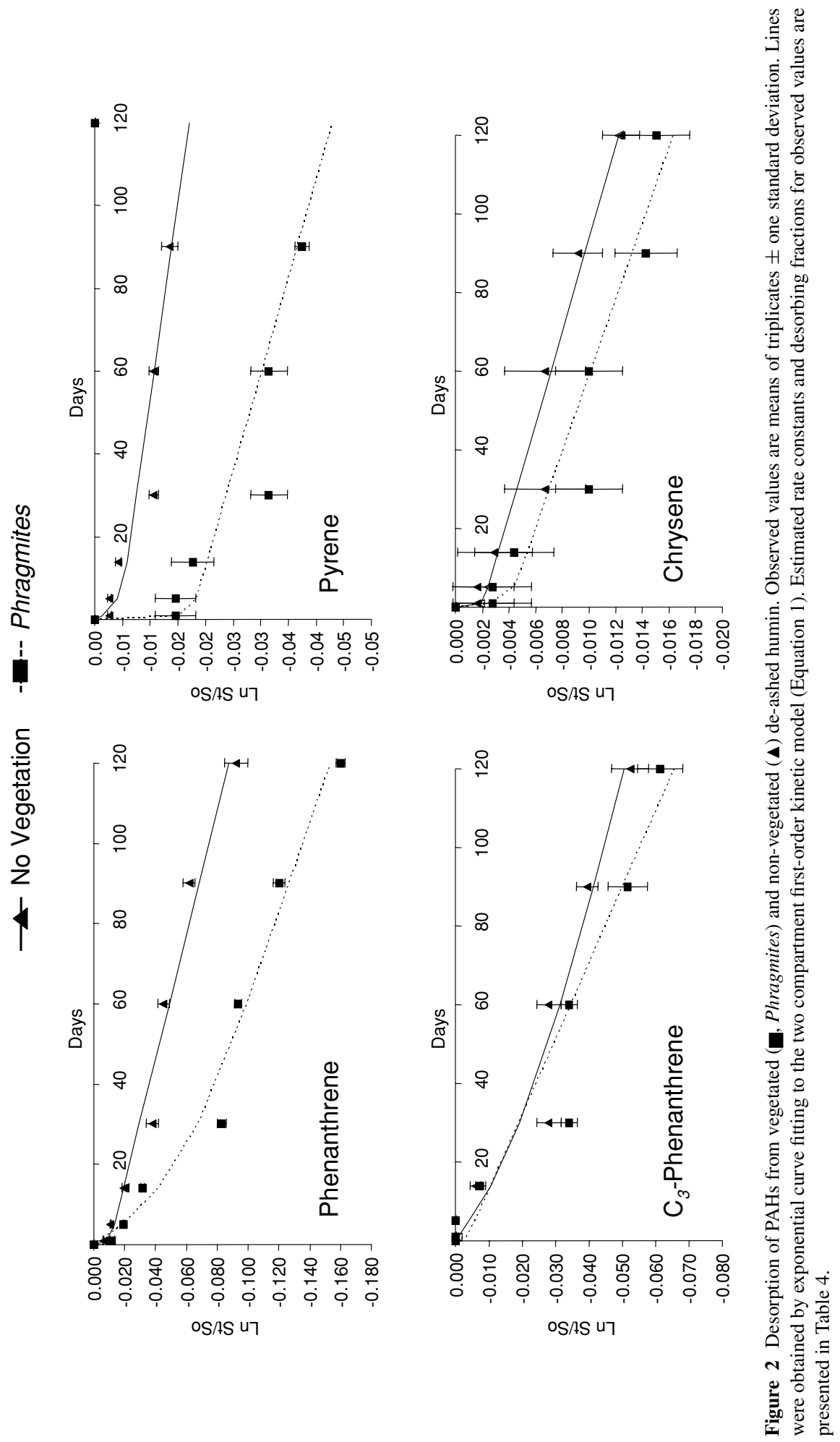


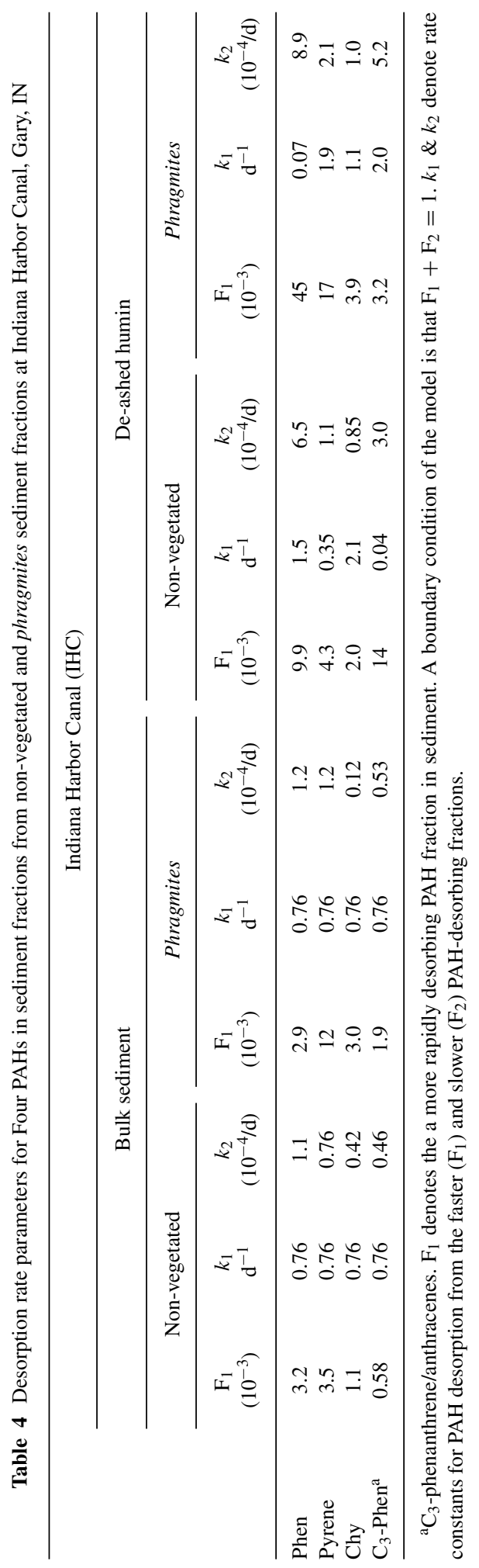


$k_{1}$ and $10^{-6} / \mathrm{h}$ to $10^{-5} / \mathrm{h}$ for $k_{2}$. PAH desorbing fractions in natural sediments can have average rate constants that range from $10^{-1}$ to $10^{-0}$ /h for "fast", $10^{-3}$ to $10^{-2} / \mathrm{h}$ for "slow," and $10^{-5}$ to $10^{-4} / \mathrm{h}$ for "very slow" (Johnson et al., 2001; Jonker et al., 2005; Oen et al., 2006). Comparison of our observed rate constants to literature values suggest that PAH release is controlled by both a "slow" $\left(\mathrm{F}_{1}\right)$ and "very slow" $\left(\mathrm{F}_{2}\right)$ desorbing PAH fraction, but that the "very slow" $\left(\mathrm{F}_{2}\right)$ fraction primarily controls PAH release. "Fast" desorbing PAH fractions are no longer present. However, the rate of PAH desorption from the "very slow," controlling $\mathrm{F}_{2}$ fraction was greater in vegetated bulk sediment and, particularly, vegetated humin fractions than non-vegetated bulk and humin fractions.

We regressed individual PAH concentrations to their respective desorbing fractions, $\log \left(\mathrm{F}_{2} / \mathrm{F}_{1}\right)$, to evaluate if PAH concentrations were associated with PAH kinetics (Oen et al., 2006). For bulk sediments, desorption was not associated with PAH concentrations $\left(r^{2}<0.001\right)$. For humin, faster desorption behavior was weakly associated with increased PAH concentrations $\left(r^{2}=0.43\right)$. Oen et al. (2006)) observed no correlation $\left(r^{2}<0.02\right)$ to weak correlations $\left(\mathrm{r}^{2}<0.29 ; \mathrm{p}<0.01\right)$ between PAH desorption kinetics and PAH concentrations in sediments. Prior studies also observed that the quantity of organic matter is a poor predictor for desorption (Shor et al., 2003; Oen et al., 2006, Kukkonen et al., 2003, Cornelissen et al., 2005) relative to other sediment characteristics. Significant correlations have been observed between desorption and either particle size or the black carbon content of sediments (Cornelissen et al., 2005), but similar BC content between vegetated and nonvegetated sediment fractions do not explain their observed differences in PAH desorption.

Shor et al. (2003) observed that PAHs rapidly diffused through sediment fractions rich in vascular plant debris, and Kukkonen et al. (2003) observed that the size of the faster desorption compartment $\left(\mathrm{F}_{1}\right)$ was directly related to the amount of plant pigment per amount of organic carbon. Li et al. (2005) also observed that indigenous microorganisms facilitate increased PAH desorption which is of interest to this study given the "rhizosphere effect" of plants on microbial abundance and activity. We observed that vegetated IHC sediments contained more plant carbon and increased PAH desorption kinetics even though these sediments were more reduced, non polar, and less oxidized than non-vegetated fractions. We propose that nonpolar, plant-derived carbon released into IHC sediments altered PAH desorption behavior and increased PAH desorption kinetics.

Plant-derived aliphatic carbon materials are integral and persistent components of SOM, particularly humin, and are preserved in soils and sediments through humification (Salloum et al., 2002). These materials have large sorptive affinities for PAHs (Chefetz et al., 2000; Salloum et al., 2002) that are correlated to their polymethylene-rich (nonpolar) content (Mao et al., 2002). Aliphatic plant carbon is thought to represent "rubbery mobile" domains of SOM into which PAHs can partition (Mao and Schmidt-Rohr, 2006). We postulate that these plant-derived aliphatic domains more rapidly sorb and desorb PAHs relative to other SOM domains present in sediment. Accordingly, the presence of these plant materials increased the faster-desorbing PAH fraction $\left(\mathrm{F}_{1}\right)$ as well as PAH desorption kinetics $\left(k_{2}\right)$ from the dominant slower desorbing PAH fraction $\left(\mathrm{F}_{2}\right)$ in IHC bulk sediment and humin.

\section{CONCLUSION}

This study emphasizes the broader chemical and physical impact of plant organic matter on contaminated organic matter composition and PAH bioavailability. We 
hypothesized that plant carbon released into IHC sediments would alter PAH desorption behavior. This study examined whether this process can occur after only a few years of plant growth. After two years of Phragmites growth in fuel-oiled sediments, vegetated sediment fractions were more reduced and non polar than non-vegetated sediments, yet PAH ratios were more weathered and PAH desorption kinetics were faster, particularly for vegetated humin. Other studies have observed that plant materials can increase soil hydrophobicity yet still enhance PAH dissipation (Cofield et al. 2007).

Our findings suggest that aliphatic plant carbon contributes nonpolar "rubbery" domains to IHC sediments that facilitate more rapid PAH desorption kinetics (Kukkonen et al., 2003; Mao and Schmidt-Rohr, 2006). This study highlights that other indices, such as overall carbon transfer from plant to soils/sediments and desorption kinetics, may indicate initial changes to organic contamination attenuation when concentration data shows little change. Rapid characterization, such as a $24 \mathrm{~h}$ desorbed fraction of PAHs (Shor et al., 2003), may be useful indices to assess the early phases of phytoremediation.

\section{ACKNOWLEDGMENTS}

We thank Pete Lazaro, Thorne Gregory, and John Fountain for their assistance with sample collection and analyses. We appreciate the comments and suggestions of reviewers to improve this manuscript. This work was supported with research funding from The National Science Foundation BES-0337453.

\section{REFERENCES}

Ahn, S.A., Werner D., and Luthy, R.G. 2005. Physiochemical characterization of coke-plant soil for the assessment of polycyclic aromatic hydrocarbon availability and the feasibility of phytoremediation. Environ. Toxicol. Chem. 24, 2185-2195.

Alexander, M. 2000. Aging, bioavailability, and overestimation of risk from environmental pollutants. Environ. Sci. Technol. 34, 4259-4265.

Asaeda, T., Nam, L., Hietz, P., Tanaka, N., and Karunaratne, S. 2002. Seasonal fluctuations in live and dead biomass of Phragmites australis as described by a growth and decomposition model, implications of duration of aerobic conditions for litter mineralization and sedimentation. Aquatic Botany 73, 223-239.

Chefetz, B., Deshmukh, A.P., Hatcher, P.G., and Guthrie, E.A. 2000. Pyrene sorption by natural organic matter. Environ. Sci. Technol. 34, 2925-2930.

Chen, B., Johnson, E.J., Chefetz, B., Zhu, L., and Xing, B. 2005. Sorption of polar and nonpolar aromatic organic contaminants by plant cuticular materials, role of polarity and accessibility. Environ. Sci. Technol. 39, 6138-6146.

Chen, B. and Xing, B. 2005. Sorption and conformational characteristics of reconstituted plant cuticular waxes on montmorillonite. Environ. Sci. Technol. 39, 8315-8323.

Cofield, N., Bank, M.K., and Schwab, A.P. 2007. Evaluation of hydrophobicity in PAH-contaminated soils during phytoremediation. Environ. Poll. 145, 60-67.

Cornelissen, G., Gustafsson, O., Bucheli, T.D., Jonker, M.T.O., Koelmans, A.A., and van Noort, P.C.M. 2005. Extensive sorption of organic compounds to black carbon, coal, and kerogen in sediments and soils: Mechanisms and consequences for distribution, bioaccumulation, and biodegradation. Environ. Sci. Technol. 39, 6881-6895.

Cornelissen, G., Rigterink, H., Ferdinandy, M.M.A., and van Noort, P.C.M. 1998. Rapidly desorbing fractions of PAHs in contaminated sediments as a predictor of the extent of bioremediation. Environ. Sci. Technol. 32, 966-970. 
Cornelissen, G., van Noort, P.C.M., and Govers, H.A.J. 1997a. Desorption kinetics of chlorobenzenes, polycyclic aromatic hydrocarbons, and polychlorinated biphenyls: Sediment extraction with Tenax ${ }^{\circledR}$ and effects of contact time and solute hydrophobicity. Environ. Toxicol. Chem. 16, 1351-1357.

Cornelissen, G., van Noort, P.C.M., Parsons, J.R., and Govers, H.A.J. 1997b. Temperature dependence of slow adsorption and desorption kinetics of organic compounds in sediments. Environ. Sci. Technol. 31, 454-460.

Denton, P.,2000. Analysis of first-order kinetics using Microsoft Excel Solver. Journal of Chemical Education 77, 1524-1525.

Gelinas, Y., Prentice, K.M., Baldcock, J.A., and Hedges, J.I. 2001. An Improved thermal oxidation method for the quantification of soot/graphitic black carbon in sediments and soils. Environ. Sci. Technol. 35, 3519-3525.

Gregory, S.T. and Guthrie Nichols, E. 2008. Differences in sediment organic matter composition and PAH weathering between non-vegetated and recently vegetated fuel-oiled sediments. International Journal of Phytoremediation (in press).

Gregory, S.T., Shea, D., and Guthrie Nichols, E. 2005. Impact of vegetation on sediment organic matter composition and polycyclic aromatic hydrocarbon attenuation. Environ. Sci. Technol. 39, 5285-5292.

Gunasekara, A.S. and Xing, B. 2003. Sorption and desorption of naphthalene by soil organic matter: Importance of aromatic and aliphatic components. J. Environ. Qual. 32, 240-246.

Huang, W., Peng, P., Yu, Z., and Fu, J. 2003. Effects of organic matter heterogeneity on sorption and desorption of organic contaminants by soils and sediments. Applied Geochem. 18, 955-972.

Huang, W. and Weber, W.L. 1997. A distributed reactivity model for sorption by soils and sediments. 10. Relationships between desorption, hysteresis, and the chemical characteristics of organic domains. Environ. Sci. Technol. 31, 2562-2569.

Jonker, M.T.O., Hawthorne, S.B., and Koelmans, A.A. 2005. Extremely slowly desorbing polycyclic aromatic hydrocarbons from soot and soot-like materials, evidenced by supercritical fluid extraction. Environ. Sci. Technol. 39, 7889-7895.

Johnson, M.D., Keinath, T.M., II, and Weber, W.J. Jr. 2001. A distributed reactivity model for sorption by soils and sediments. 14. Characterization and modeling of phenanthrene desorption rates. Environ. Sci. Technol. 35, 1688-1695.

Kan, A.T., Chen, W., and Tomson, M.B. 2000. Desorption kinetics of neutral hydrophobic organic compounds from field contaminated sediment. Environmental Pollution 108, 81-89.

Kang, S. and Xing, B. 2005. Phenanthrene sorption to sequentially extracted soil humic acids and humins. Environ. Sci. Technol. 39, 134-140.

Kile, D.E., Wershaw, R.L., and Chiou, C.T. 1999. Correlation of soil and sediment organic matter polarity to aqueous sorption of nonionic compounds. Environ. Sci. Technol. 33, 2053-2056.

Kukkonen, J.V.K., Landrum, P.F., Mitra, S., Gossiaux, D.C., Gunnarsson, J., and Weston, D. 2003. Sediment characteristics affecting desorption kinetics of select PAH and PCB congeners for seven laboratory spiked sediments. Environ. Sci. Technol. 37, 4656-4663.

Li, J., Pignatello, J.J., Smets, B.F., Grasso, D., and Monserrate, E.,2005. Bench-scale evaluation of in situ bioremediation strategies for soil at a former manufactured gas plant site. Environmental Toxicology and Chemistry 24, 741-749.

Luellen, D. and Shea, D.,2002. Calibration and field verification of semipermeable membrane devices for measuring polycyclic aromatic hydrocarbons in water. Environ. Sci. Technol. 36, 1791-1797.

Mao, J.D., Hundal, L.S., Thompson, M.L., and Schmidt-Rohr, K. 2002. Correlation of poly(methylene)rich amorphous aliphatic domains in humic substances with sorption of a nonpolar organic contaminant, phenanthrene. Environ. Sci. Technol. 36, 929-936.

Mao, J.D. and Schmidt-Rohr, K. 2006. Absence of Mobile Carbohydrate Domains in Dry Humic Substances Proven by NMR, and Implications for Organic-Contaminant Sorption Models. Environ. Sci. Technol. 40, 1751-1756. 
Minchinton, T. 2002. Disturbance by wrack facilitates spread of Phragmites australis in a coastal marsh. Journal of Experimental Marine Biology and Ecology 281, 89-107.

Oen, A.M.P., Breedveld, G.D., Kalaitzidis, S., Christanis, K., and Cornelissen, G. 2006. How quality and quantity of organic matter affect polycyclic aromatic hydrocarbon desorption from Norwegian harbor sediments. Environ. Toxicol. Chem. 25, 1258-1267.

Oren, A. and Chefetz, B.,2005. Sorption-desorption behavior of polycyclic aromatic hydrocarbons in upstream and downstream river sediments. Chemosphere 61, 19-29.

Pignatello, J.J. 1990. Slowly reversible sorption of aliphatic halocarbons in soils. I. Formation of residual fractions. Environ. Toxicol. Chem. 9, 1107-1115.

Pignatello, J.J. and Xing, B. 1996. Mechanisms of slow sorption of organic chemicals to natural particles. Environ. Sci. Technol. 30, 1-11.

Rockne, K.J., Shor, L.M., Young, L.Y., Taghon, G.L., and Kosson, D.S. 2002. Distributed sequestration and release of PAHs in weathered sediment: The role of sediment structure and organic carbon properties. Environ. Sci. Technol. 36, 2636-2644.

Rutherford, D.W., Chiou, C.T., Kile, D.E. 1992. Influence of soil organic matter composition on the partition of organic compounds. Environ. Sci. Technol. 26, 336-340.

Saffron, C.M., Park, J.H., Dale, B.E., and Voice, T.C. 2006. Kinetics of contaminant desorption from soil: comparison of model formulations using the akaike information criterion. Environ. Sci. Technol. 40, 7662-7667.

Salloum, M.J., Chefetz, B., and Hatcher, P.G. 2002. Phenanthrene sorption by aliphatic-rich natural organic matter. Environ. Sci. Technol. 36, 1953-1958.

Sand Creek Consultants, Inc. 2002. Indiana Harbors Canal Phytoremediation Treatability Study Year End Report (2002), Rhinelander, WI, 46 pages.

Shor, L.M., Rockne, K.J., Taghon, G.L., Young, L.Y., and Kosson, D.S. 2003. Desorption kinetics for field-aged polycyclic aromatic hydrocarbons from sediments. Environ. Sci. Technol. 37, $1535-1544$.

United States Environmental Protection Agency. 1986. SW-846 Manual for Waste Testing, Volumes $1 \mathrm{~B}$ and $1 \mathrm{C}$. Washington, D.C., USEPA.

Van Den Heuvel, H. and van Noort, P.C.M. 2003. Competition for adsorption between added phenanthrene and in situ PAHs in two sediments. Chemosphere 53, 1097-1103.

Wakeham, S.G., Forrest, J., Masiello, C., Gelinas, Y., Alexander, C.R., and Leavitt, P.R. 2004. Hydrocarbons in Lake Washington sediments. A 25-year retrospective in an urban lake. Environ. Sci. Technol. 36, 38, 431-439.

Wang, X., Sato, T., and Xing, B. 2005. Sorption and displacement of pyrene in soils and sediments. Environ. Sci. Technol. 39, 8712-8718.

White, J.C. and Pignatello, J.J. 1999. Influence of bisolute competition on the desorption kinetics of polycyclic aromatic hydrocarbons in soil. Environ. Sci. Technol. 33, 4292-4298.

White, J.C., Kelsey, J.W., Hatzinger, P.B., and Alexander, M. 1997. Factors affecting sequestration and bioavailability in soils. Environ. Toxicol. Chem. 16, 2040-2045.

Xing, B., McGill, W.B., and Dudas, M.J. 1994. Cross-correlation of polarity curves to predict partition coefficients of nonionic organic contaminants. Environ. Sci. Technol. 28, 1929-1933.

Yang, C., Huang, W., Xiao, B., Yu, Z., Peng, P., Fu, J., and Sheng, G. 2004. Intercorrelations among degree of geochemical alterations, physicochemical properties, and organic sorption equilibria of kerogen. Environ. Sci. Technol. 38, 4396-4408. 